\title{
Postdated pregnancy: its maternal and fetal outcome
}

\author{
Neetu Singh*, Devyani Misra, Shubhi Srivastava
}

\begin{abstract}
Department of Obstetrics and Gynecology, Dr. Ram Manohar Lohia Institute of Medical Sciences, Lucknow, Uttar
\end{abstract} Pradesh, India

Received: 18 May 2020

Accepted: 29 June 2020

*Correspondence:

Dr. Neetu Singh,

E-mail: drneetusingh73@gmail.com

Copyright: () the author(s), publisher and licensee Medip Academy. This is an open-access article distributed under the terms of the Creative Commons Attribution Non-Commercial License, which permits unrestricted non-commercial use, distribution, and reproduction in any medium, provided the original work is properly cited.

\begin{abstract}
Background: Postdated pregnancy is one of the commonest obstetric conditions. Pregnancy is called term when it lies between 37 weeks to 42 weeks from the last menstrual period. If the pregnancy exceeds 40 weeks it is called as postdated pregnancy. The overall incidence of post term pregnancy is $7 \%$ of all pregnancies.

Methods: This observational study was carried out in the department of obstetrics and gynecology in Dr Ram Manohar Lohia Institute of Medical Sciences, Lucknow, Uttar Pradesh, India from September 2019 to February 2020. Total 100 postdated pregnancy enrolled in the study those willing to participate and fulfilling the inclusion and exclusion criteria. Aim is to assess maternal and fetal outcome in postdated pregnancy.

Results: In present study, incidence of postdated pregnancy was found to be 5\% and number of normal deliveries was $66(66 \%)$, LSCS were $32(32 \%)$ and $2(2 \%)$ were instrumental delivery. Maternal complications were seen in 14 $(14 \%)$ cases and fetal complications were found in $23(23 \%)$ cases.

Conclusions: Postdated pregnancy was associated with perinatal complications like fetal distress, meconium aspiration syndrome and fetal asphyxia. There was increased risk of obstetrics complications like postpartum haemorrhage (PPH), perineal tear, cervical tear and shoulder dystocia. Management of postdated pregnancy is a challenge to obstetrician and a careful advice and monitoring can alleviate maternal anxiety and untoward complications.
\end{abstract}

Keywords: Last menstrual period, Maternal complication, Postdated, Pregnancy outcome

\section{INTRODUCTION}

Postdate, postterm, postmaturity, and prolonged pregnancy is accepted terms by WHO and the International Federation of Gynecology and Obstetrics to describe pregnancy beyond dates (expected date of delivery). As per WHO, postterm pregnancy (PTP) is defined as a pregnancy that persists beyond 294 days or 42 weeks of gestation. ${ }^{1}$ The reported frequency of PTP is approximately $7 \% .^{2}$ The prevalence varies depending on population characteristics and local management practices. The incidence of PTP varies depending on whether the calculation is based on the history and clinical examination alone, or whether early pregnancy ultrasound examination is used to estimate gestational age. ${ }^{3,4}$ The assessment of the gestational age by early ultrasound examination has reduced the "incidence" of PTP by $50.0 \% .^{5}$

Postdated pregnancies may be due to multiple etiologies. Exact etiology is not known but some risk factors are associated with post term pregnancy like parity, maternal age, past history of post term pregnancy, genetics and obesity. ${ }^{6,7}$ Management protocol for postterm pregnancy is fetal surveillance for prolonged pregnancy, induction of labour, during intrapartum care proper monitoring of labour. $^{8}$

Complications to both mother and fetus are seen in postdated pregnancies. It has been reported that in a 
pregnancy which has crossed the expected date of delivery; there is an increased risk of oligohydramnios, meconium stained amniotic fluid, macrosomia, fetal postmaturity syndrome, and caesarean delivery, all of which jeopardize the baby as well as the mother. Prolonged pregnancy has always been regarded as a highrisk condition because perinatal morbidity and mortality is known to rise. ${ }^{9}$ The aim of the present study was to analyse the incidence and outcome of pregnancies which crossed the expected date of delivery.

\section{Aims and objectives}

- To evaluate the incidence of postdated pregnancy

- To assess maternal and fetal outcome in postdated pregnancy.

\section{METHODS}

This was a prospective observational study carried out in the department of obstetrics and gynecology, Dr. Ram Manohar Lohia Institute of Medical Sciences, Lucknow, Uttar Pradesh, India from September 2019 to February 2020 for a period of 6 months. Written informed consent was taken from the patient. A total 100 patients were included with non-random sampling method.

\section{Inclusion criteria}

- Pregnant women more than 40 weeks of gestation (last three menstrual cycles regular, not used contraceptive pills for the past 3 months, not conceived during lactational amenorrhea)

- Singleton pregnancy

- Cephalic presentation

- The patients who have given written informed consent to participate in this study were included.

\section{Exclusion criteria}

- Any associated complications such as previous lower segment cesarean section (LSCS), malpresentations, placenta previa, abruption, PIH, gestational diabetes, anaemia, and other medical complications

- Fetal anomalies.

Postdated pregnant patients fulfilling my inclusion and exclusion criteria were included in the study. Detailed history was obtained from the patient about the socioeconomic status, booked/unbooked, the patient's age, obstetric code, gestational age, menstrual history, obstetric history. General physical examination, systemic examination and obstetric examination was carried out. Per speculum and per vaginal examination was done. Blood investigations - complete blood counts, liver function tests, kidney function tests, blood sugar, blood grouping, urine analysis, HIV, VDRL, HBsAg, HCV were done. USG Doppler and NST were done. Decision of delivery route was done as required. Some patients were already in spontaneous labour, some were subjected to induction of labour. If delivery was by caesarean section, the indication was recorded. Perinatal morbidity by low Apgar score meconium aspiration syndrome, neonatal intensive care unit (NICU) admission and mortality if any was recorded. Maternal complications such as postpartum haemorrhage, perineal tear, etc were also recorded.

\section{RESULTS}

Out of 1986 patients delivered, there were 100 postdated deliveries so the frequency of postdated pregnancy was $5 \%$. Maximum $72(72 \%)$ cases were of age group 20-25 years, $18(18 \%)$ cases were of age group 26-30 years, and $9(9 \%)$ cases were of age group 31-35 years. Majority cases were primigravida $(68 \%)$ with rural background (57\%). Most of the patients belonged to lower middle class $(16 \%)$ and upper lower class $(52 \%)$ (Table 1$)$.

Table 1: Demographic distribution.

\begin{tabular}{|lll|}
\hline Age (years) & No. of cases $(\mathbf{N})$ & Percentage \\
\hline $20-25$ & 72 & 72 \\
\hline $26-30$ & 18 & 18 \\
\hline $31-35$ & 9 & 9 \\
\hline$>35$ & 1 & 1 \\
\hline Parity & \\
\hline Primigravida & 68 & 68 \\
\hline P2 & 22 & 22 \\
\hline P3 & 6 & 6 \\
\hline$>$ P3 & 4 & 4 \\
\hline Socioeconomic status & \\
\hline I & 1 & 1 \\
\hline II & 9 & 9 \\
\hline III & 22 & 22 \\
\hline IV & 52 & 52 \\
\hline V & 16 & 16 \\
\hline Residence & & \\
\hline Rural & 57 & 57 \\
\hline Urban & 43 & 43 \\
\hline
\end{tabular}

Table 2: Comparison of mode of delivery with gestational age.

\begin{tabular}{|lllllll|}
\hline Gestational age & $\mathbf{N D}(\mathbf{n}=\mathbf{6 6})$ & \multicolumn{2}{c|}{ LSNCS $(\mathbf{n = 3 2})$} & \multicolumn{2}{c|}{ Instrumental delivery } \\
\hline & $\mathbf{N}$ & $\mathbf{\%}$ & $\mathbf{N}$ & $\mathbf{\%}$ & $\mathbf{N}$ & $\mathbf{\%}$ \\
\hline 40-week 1 day-41 weeks & 56 & 84 & 23 & 71 & 2 & 2 \\
\hline 41-week 1 day-42 weeks & 8 & 12 & 6 & 18 & 0 & 0 \\
\hline$>$ 42 weeks & 2 & 4 & 3 & 1 & 0 & 0 \\
\hline
\end{tabular}


Maximum, i.e., $81(81 \%)$ cases were of gestational age between 40 weeks 1 day and 41 weeks, 14 (14\%) cases were of gestational age between 41 weeks 1 day and 42 weeks and $5(5 \%)$ were of gestational age $>42$ weeks. Total number of normal deliveries (ND) were $66(66 \%)$, out of which $56(84 \%)$ cases were of gestational age 40 weeks 1 day to 41 weeks, $8(12 \%)$ cases were of gestational age 41 weeks 1 day to 42 weeks and $2(3 \%)$ cases were of gestational age $>42$ weeks. Total number of instrumental deliveries were in only $2(2 \%)$, occurred in gestational age 40 weeks 1 day to 41 weeks. Total number of caesarean sections were $32(32 \%)$, out of which $23(71 \%)$ cases were of gestational age 40 weeks 1 day to 41 weeks, $6(18 \%)$ cases were of gestational age 41 weeks 1 day to 42 weeks and $3(9 \%)$ cases were of gestational age $>42$ weeks (Table 2 ).

Total number of caesarean sections were 32 (32\%) cases. Indication was meconium stained liquor with meconium stained liquor with fetal distress in 8 (26\%), 7 (21\%) cases were for failure of induction, $6(19 \%)$ cases were for severe oligohydramnios, $5(15 \%)$ cases were for cephalopelvic disproportion and $5(15 \%)$ cases were for nonprogress of labor. In $1(3 \%)$ case indication was absent liquor (Table 3).

Table 3: Indication for caesarean section.

\begin{tabular}{|lll|}
\hline Indication & No. of cases & $\%$ \\
\hline Absent liquor & 1 & 3 \\
\hline Cephalopelvic disproportion & 5 & 15 \\
\hline Failure of induction & 7 & 21 \\
\hline $\begin{array}{l}\text { Meconium stain liquor with } \\
\text { fetal distress }\end{array}$ & 8 & 26 \\
\hline Severe oligohydramnios & 6 & 19 \\
\hline Non progress of labour & 5 & 15 \\
\hline
\end{tabular}

Table 4: Maternal complications.

\begin{tabular}{|lll|}
\hline Maternal complication & No. of cases & $\%$ \\
\hline Postpartum haemorrhage & 6 & 6 \\
\hline Perineal tear & 5 & 5 \\
\hline Cervical tear & 2 & 2 \\
\hline Shoulder dystocia & 1 & 1 \\
\hline
\end{tabular}

Table 5: Fetal complications.

\begin{tabular}{|lll|}
\hline Fetal complication & No. of cases & $\%$ \\
\hline Meconium aspiration syndrome & 7 & 7 \\
\hline Respiratory distress syndrome & 8 & 8 \\
\hline Macrosomia & 4 & 4 \\
\hline Hyperbilirubinemia & 2 & 2 \\
\hline Neonatal death & 2 & 2 \\
\hline
\end{tabular}

Maternal complications were present in 14 (14\%) cases. Postpartum haemorrhage was found in $6(6 \%)$ cases, perineal tear was present in $5(5 \%)$ and cervical tear was found in $2(2 \%)$ cases and shoulder dystocia was found in $1(1 \%)$ case (Table 4$)$.

Fetal complications were found in 23 (23\%) cases. meconium aspiration syndrome was found in in $7(7 \%)$ cases, respiratory distress syndrome was found in $8(8 \%)$ cases, macrosomia was present in $4(4 \%)$ cases and hyperbilirubinemia was found in $2(2 \%)$ cases. There were $2(2 \%)$ neonatal death in this study (Table 5).

\section{DISCUSSION}

The present study was conducted to find out the incidence of maternal complications, perinatal mortality and morbidity in postdated pregnancies. Total cases were 100 which were enrolled based on inclusion and exclusion criteria.

Out of 1986 patients delivered, there were 100 postdated deliveries so the frequency of postdated pregnancy was $5 \%$. In this study maximum cases $(72 \%)$ were in between 20-25 years, while $18 \%$ were in between 26-30 year of age. Akhtar $\mathrm{P}$ et al, observed in their study on pregnancy beyond 41 weeks of gestation that $82 \%$ of cases were in the age group of 18 to 29 years. ${ }^{10,15}$ In study by Dobariya PV et al, there were $58(69.05 \%)$ patients in age group 20 to 30 years, and in study by Patel $\mathrm{N}$ et al, there were 32 $(64 \%)$ cases in age group 20 to 30 years. ${ }^{11,12,16,17}$ Maximum women $(68 \%)$ were primigravida in this study similarly Mahapatro et al, found maximum (72\%) of patients were primigravida. ${ }^{13,14}$ Alfirevic and Walkinshaw, Morgreaset et al, found in their study that primiparity was significantly associated with postterm pregnancy. ${ }^{14,15}$ In this study maximum women(57\%) were belonged to rural area and $43 \%$ were belonged to urban area. Improper antenatal checkups were observed in rural women and mostly they came directly in labour.

In this study maximum women $81 \%$ were in between $40+1$ to 41 weeks of gestation age, $14 \%$ were in between 41-42 weeks of gestation age and $5 \%$ were in between more than 42 weeks of gestation age. In studies done by Patel $\mathrm{N}$ et al, maximum patients were between 40 to 40.6 weeks which is similar to this study. ${ }^{12}$ In this study maximum cases $(66 \%)$ were delivered normally, caesarean section were performed in $32 \%$ while in $2 \%$ instrumental delivery were performed. Women with uncomplicated pregnancies should be offered induction of labour, while women with any complicating factors LSCS should be considered. Shinge $\mathrm{N}$ et al, studied that maximum patients $(53.7 \%)$ underwent spontaneous vaginal delivery, $9.5 \%$ patients required instrumental delivery and $37 \%$ patients required caesarean section as mode of delivery. ${ }^{16,22}$ The rate of instrumental delivery in this study was 2\%, whereas in Mahapatro's study it was found to be $5.72 \% .^{13}$

In the present study, indication for caesarean section was meconium stained liquor with fetal distress in 8 patients $(26 \%)$ and failure of induction in 7 cases $(21 \%)$, which 
were followed by cephalo-pelvic disproportion in 5 cases (16\%), severe oligohydramnios in 6 patient (19\%) and non-progress of labour in $5(15 \%)$. Mahapatro's study, in which fetal distress was found to be the most common indication for LSCS $(65.5 \%) .{ }^{13}$ In the study by Akhtar P et al, caesarean section was done in view of fetal distress in $32 \%$ cases, non-progress of labour in $25.3 \%$ cases and failure of induction in $24 \%$ cases. $^{10}$

In this study most common (6\%) complication was postpartum haemorrhage $(\mathrm{PPH})$. Others were perineal tear in $5 \%$, cervical tear in $2 \%$ of cases and shoulder dystocia was seen in $1 \%$. In study conducted by Patel $\mathrm{N}$ et al, maximum morbidity was because of perineal tears/cervical tears in 10 patients $(34.44 \%)$ and prolonged labour/shoulder dystocia in 10 patients $(34.44 \%)$ followed by postpartum haemorrhage in 6 patients $(20.47 \%){ }^{12}$ There was no maternal mortality.

In this study meconium aspiration syndrome was the most common fetal complication found in $8 \%$ of cases, while respiratory distress syndrome was present in $7 \%$, macrosomia in 4\%, hyperbilirubinemia in $2 \%$ and neonatal death was found in 2 cases. Meconium aspiration syndrome refers to respiratory compromise with tachypnea, cyanosis, and reduced pulmonary compliance in newborn infants exposed to meconium in utero. It is seen in higher rates in postterm neonates (Kabbur et al). ${ }^{17}$ Postterm infants are larger than term infants and have a higher incidence of fetal macrosomia (2.5-10\% in postterm versus $0.8-1 \%$ at term) this was stated by Spellacy et al Rosen and Dickinson. ${ }^{18,19}$

NICU admission rate is high as compared to general population (12.5\%). As per various studies, NICU admission rate is increased in postdated pregnancies. Most common indication being of NICU admission being asphyxia neonatorum.

Neonatal mortality rate in present study is $2 \%$, while Perinatal mortality according to Akhter $\mathrm{S}$ and Thakur et al, is $5.4 \%$, is $3 \% .^{20,21,24,25}$ Neonatal death was because of meconium aspiration syndrome as she came later in labour with leaking per vaginum having thick meconium stained liquor since 12 hours.

Risks such as stillbirth, passage of meconium, and neonatal acidemia have been described as being greater at 41 and even 40 weeks of gestation as compared to 39 weeks gestation Caughy et al, Caughey and Musci. ${ }^{22,23}$

\section{CONCLUSION}

Postdated pregnancy is associated with fetal, neonatal and maternal complications including morbidity and perinatal mortality. The use of routine ultrasound for dating in the first trimester has decreased the overall rate of postdated pregnancy. Postdated pregnancies require early detection, effective and proper planning management to reduce maternal and neonatal morbidity. The mere fact that the pregnancy is postdated does not necessitate a hasty line of management towards operative delivery. More trainings of peripheral health worker is required for calculation of accurate dating, making diagnosis and proper management to reduce its incidence.

\section{Funding: No funding sources \\ Conflict of interest: None declared \\ Ethical approval: Not required}

\section{REFERENCES}

1. Balakrishnan S. Textbook of Obstetrics. Hydrabad, India: Paras Medical Publishers; 2013: 218.

2. Neff MJ. ACOG releases guidelines on management of post-term pregnancy. Am Fam Physician. 2004;70:2221-5.

3. Eik-Nes SH, Okland O, Aure JC, Ulstein M. Ultrasound screening in pregnancy: a randomised controlled trial. Lancet. 1984;1:1347.

4. Ingemarsson I, Hedén L. Cervical score and onset of spontaneous labor in prolonged pregnancy dated by second-trimester ultrasonic scan. Obstet Gynecol 1989;74:102-5.

5. Marahatta R, Tuladhar H, Sharma S. Comparative study of post term and term pregnancy in Nepal Medical College Teaching Hospital (NMCTH). Nepal Med Coll J. 2009;11:57-60.

6. Divon MY, Haglund B, Nisell H, Otterblad PO, Westgren M. Fetal and neonatal mortality in the postterm pregnancy: the impact of gestational age and fetal growth restriction. Am J Obstet Gynecol. 1998;178(4):726-31.

7. Van Eyk N, Allen LM, Sermer M, Davis VJ. Obstetric outcome of adolescent pregnancies. J Pediatr Adolescent Gynecol. 2000;13(2):96.

8. Mandruzzato G, Alfirevic $Z$, Chervenak F, Gruenebaum A, Heimstad R, Heinonen S. Guidelines for the management of postterm pregnancy. J Perinat. Med.2010:38(2010)111-9.

9. Grant JM. Induction of labour confers benefits in prolonged pregnancy. $\mathrm{Br} \mathrm{J}$ Obstet Gynaecol. 1994;101:99-102.

10. Akhter P, Sultana M, Hoque M, Sultata S, Khatun MR, Dabee SR. Maternal outcome of prolonged pregnancy. J Bangladesh Coll Phys Surg. 2014;32(2):66.

11. Dobariya PV, Shah PT, Ganatra HK. Feto-maternal outcome in pregnancy beyond 40 weeks. Int $\mathbf{J}$ Reprod Contracept Obstet Gynecol. 2017;6(2):52731.

12. Patel N, Modi P. A Study of maternal and fetal outcome in postdate pregnancy. Int $\mathbf{J}$ Sci Res. 2017;6(9):2015-8.

13. Mahapatro A, Samal S. Fetomaternal outcome in pregnancy beyond 40 week. Int J Pharma Bio Sci. 2015;6(2):53-8.

14. Alfirevic Z, Walkinshaw SA. Management of postterm pregnancy: to induce or not? Br J Hosp Med. 1994;52:218-21. 
15. Mogren I, Stenlund H, Hogberg U. Recurrence of prolonged pregnancy. Int J Epidemiol. 1999;28:2537

16. Shinge N, MM VK, Prashanth S. Comparative study of maternal and fetal outcome in pregnancies of gestational age 40 completed weeks and beyond. J Evol Med Dent Sci. 2013;2(25):4509-16.

17. Kabbur PM, Herson VC, Zaremba S, Lerer T. Have the year 2000 neonatal resuscitation program guidelines changed the delivery room management or outcome of meconium-stained infants? J Perinatol. 2005;25:694-7.

18. Spellacy WN, Miller S, Winegar A, Peterson PQ. Macrosomia - maternal characteristics and infant complications. Obstet Gynecol. 1985;66:158-61.

19. Rosen MG, Dickinson JC. Management of post-term pregnancy. N Engl J Med. 1992;326.

20. Akhter S. Maternal and perinatal outcome in postdated pregnancy: a study of 100 cases in
Bangladesh armed forces. J Armed Forces Med Coll Bangladesh. 2014:10(1):39-44.

21. Thakur R, Kelkar YV, Shrivastava N. Perinatal risk in postdated pregnancy. Presented in $29^{\text {th }}$ AICOG 1985.

22. Caughey $A B$, Washington AE, Laros RK. Neonatal complications of term pregnancies: rates increase in a continuous, not threshold fashion. Am J Obstet Gynecol. 2005;192(1):185-9

23. Caughey AB, Musci TJ. Complications of term pregnancies beyond 37 weeks of gestation. Obstet Gynecol. 2004;103:57-62.

Cite this article as: Singh N, Misra D, Srivastava S. Postdated pregnancy: its maternal and fetal outcome. Int J Reprod Contracept Obstet Gynecol 2020;9:3223-7. 